\title{
Research of heat resistance of the multilayer coating after electro- spark alloying of C45 steel Cr-Ni alloys
}

\author{
A. V. Kozyr ${ }^{1}$, L. A. Konevtsov ${ }^{2}$, S. V. Konovalov ${ }^{3,4, \dagger}$, S. V. Kovalenko ${ }^{5}$, V. I. Ivashenko ${ }^{1}$ \\ †ksv@ssau.ru \\ ${ }^{1}$ Amur State University, 21 Ignatievskoe sh., Blagoveshensk, 675027, Russia \\ ${ }^{2}$ Institute for Material Studies, Far East Branch of RAS, 153b Tikhookeanskaya st., Khabarovsk, 680042, Russia \\ ${ }^{3}$ Samara National Research University, 34, Moskovskoye sh., Samara, 443086, Russia \\ ${ }^{4}$ Wuhan Textile University, 1 Fang Zhi Road, Wuhan, 430073, China \\ ${ }^{5}$ Pacific National University, 136, Tikhookeanskaya st., Khabarovsk, 680035, Russia
}

\begin{abstract}
Electrospark alloying by chromium-nickel steels X12CrNiTi18-9, X8Cr22Ni6Ti, X20CrNi72, X20Cr13, 12Ni14, heat-resistant alloy NiCr80-20 and pure metals $\mathrm{Cr}$ and $\mathrm{Ni}$ of steel 45 samples has been carried out. It is established that the resistance to oxidation of the formed doped layer in the temperature range $25-1000^{\circ} \mathrm{C}$ depends on the combination of alloying elements of $\mathrm{Ni}$ and $\mathrm{Cr}$, transferred from the anode material during electrospark alloying. The resistance of the samples to gas corrosion during a differential thermal analysis in the temperature range $25-1000^{\circ} \mathrm{C}$ and a heat-resistant test for 7 hours at $730^{\circ} \mathrm{C}$ in a series of doped layers formed by $\mathrm{Cr}, \mathrm{Cr}-\mathrm{Ni}$ alloy, heat-resistant steels is analyzed and it is shown that the chrome coating exhibits the highest resistance to thermal action. It has been proved that the chemical composition of the doped layer rather than its macroparameters, namely continuity, porosity and thickness, has a primary importance for the ability of electrospark coatings to resist high temperature for a long period of time. The conditions for the formation of a heat-resistant protective layer on steel 45 are determined: a) the presence of unlimited solid solutions based on $\mathrm{Cr}, \mathrm{Ni}$, and Fe in the structure of the doped layer; b) ratio of the elements in the doped layer: $\mathrm{Cr}-15 \mathrm{wt} \%$ and $\mathrm{Ni}-40 \mathrm{wt} \%$. The most balanced ratio of elements in the doped layer ( $\mathrm{Cr} 15 \mathrm{wt} \%$ and $\mathrm{Ni} 40 \mathrm{wt} \%$ ) is established that is capable of forming doped layer protective structures based on $\mathrm{Cr}_{2} \mathrm{O}_{3}, \mathrm{NiO}, \mathrm{NiCr}_{2} \mathrm{O}_{4}$ on the surface, to resist oxidation and to protect the substrate of structural steels. It is proposed to use as alloying material the NiCr80-20 alloy, which provides in the process of electrospark alloying a balanced ratio of $\mathrm{Cr}$ and $\mathrm{Ni}$ in the doped layer of steel 45 for the formation of heat-resistant protection.
\end{abstract}

Keywords: electrospark alloying, electrode materials, heat resistance, gas corrosion, nickel-chromium alloys.

УДК 669.1

\section{Исследование жаростойких свойств покрытий после электро- искрового легирования стали 45 хромоникелевыми сплавами}

\author{
Козырь А. В. ${ }^{1}$, Коневцов Л. А. ${ }^{2}$, Коновалов С. В. ${ }^{3,4,}$, Коваленко С. В. ${ }^{5}$, Иващенко В. И. ${ }^{1}$ \\ ${ }^{1}$ Амурский государственный университет, Игнатьевское шоссе, 21, Благовещенск, 675027, Россия \\ ${ }^{2}$ Институт материаловедения ХНЦ ДВО РАН, ул. Тихоокеанская, 153, Хабаровск, 680042, Россия \\ ${ }^{3}$ Самарский национальный исследовательский университет им. акад. С. П. Королева, \\ Московское шоссе, 34, Самара, 443086, Россия \\ ${ }^{4}$ Уханьский текстильный университет, 1 Fang Zhi Road, Ухань, 430073, КНР \\ ${ }^{5}$ Тихоокеанский государственный университет, ул. Тихоокеанская, 136, Хабаровск, 680035, Россия
}

Проведено электроискровое легирование хромоникелевыми сталями 12Х18Н10Т, 08Х22Н6Т, 14Х17Н2, 20Х13, 12ХН3А, жаростойким сплавом Х20H80-Н и чистыми металлами $\mathrm{Cr}$ и $\mathrm{Ni}$ на образцах из стали 45 . Установлено, что стойкость к окислению сформированного легированного слоя в интервале температур $25-1000^{\circ} \mathrm{C} 3 а в и с и т$ от комбинации легирующих элементов $\mathrm{Ni}$ и $\mathrm{Cr}$, передаваемой материалом анода при электроискровом легировании. Проанализировано сопротивление образцов газовой коррозии при проведении дифференциального термического анализа в интервале температур $25-1000^{\circ} \mathrm{C}$ и жаростойкого испытания в течение 7 часов при $730^{\circ} \mathrm{C}$ в ряду легированных слоев, образуемых хромом, хромоникелевым сплавом, жаростойкими сталями. Показано, что хромовое покрытие проявляет наибольшую стойкость к термическому воздействию. Доказано, что на способность электроискровых покрытий длительно сопротивляться высокой температуре оказывает приоритетное значение химиче- 
ский состав легированного слоя, а не его макропараметры, такие как сплошность, пористость толщина. Определены условия формирования термостойкого защитного слоя на стали 45: а) наличие неограниченных твердых растворов на основе $\mathrm{Cr}, \mathrm{Ni}, \mathrm{Fe}$ в структуре легированного слоя; б) соотношение элементов в легированном слое - $\mathrm{Cr}(15 \mathrm{Bec} \%)$ и $\mathrm{Ni}(40$ вес.\%). Установлено наиболее сбалансированное соотношение элементов в легированном слое Сr 15 вес.\% и $\mathrm{Ni} 40$ вес.\%, способное при термическом воздействии формировать на поверхности легированного слоя защитные структуры на основе $\mathrm{Cr}_{2} \mathrm{O}_{3}, \mathrm{NiO}, \mathrm{NiCr}_{2} \mathrm{O}_{4}$, сопротивляться окислению и защищать подложку из конструкционных сталей. Предложено использовать в качестве легирующего материала сплав Х20H80-Н, обеспечивающий в процессе электроискрового легирования сбалансированное соотношение $\mathrm{Cr}$ и $\mathrm{Ni}$ в легированном слое стали 45 для формирования жаростойкой защиты.

Ключевые слова: электроискровое легирование, электродные материалы, жаростойкость, газовая коррозия, хромоникелевые сплавы.

\section{1. Введение}

Известно, что метод электроискрового легирования используется для защиты конструкционных сталей и сплавов от газовой коррозии, обеспечивая малую химическую активность измененного поверхностного слоя деталей [1-8]. Измененный поверхностный слой - это слой, возникающий на поверхности детали (катода) в результате ее взаимодействия с легирующими элементами анода. При этом хороший защитный эффект наблюдается при использовании в качестве материалов легирующих электродов (анодов) как чистых металлов $\mathrm{Cr}$, Al, так и сплавов феррокремний, феррохром [6, 8-10]. Однако их использование сопровождается строгими требованиями к сплошности, пористости и шероховатости сформированных покрытий, предполагая влияние этих характеристик на способность модифицированных деталей противостоять газовой коррозии. Ранее отмечалась возможность формирования легированного слоя при электроискровом легировании на сталях 35 и 45 достаточной толщины, сплошности, малой пористости и шероховатости, при использовании в качестве материала легирующего электрода хромоникелевых сплавов, образующих неограниченные твердые растворы $[10,15]$. Были изучены условия формирования легированного слоя, фазовый состав и микроструктура покрытий после электроискрового легирования хромоникелевыми сплавами в сравнении с чистыми металлами, предложены критерии оценки эффективности данного процесса [10-17]. Однако исследования по влиянию повышенных температур на свойства легированного слоя выполнены не были.

Целью настоящей работы являлось исследование окисляемости, жаростойкости и структуры покрытий, сформированных на стали 45 электроискровым легированием хромоникелевыми сталями и сплавами.

\section{2. Материалы и методики исследования}

Электроискровое легирование осуществляли на установке IMES-01-2, разработанной и выполненной Институтом материаловедения ХНЦ ДВО РАН. Электроискровое легирование производилось на воздухе при энергии в импульсе $W=0,512$ Дж и частоте следования импульсов 400 Гц. Время формирования легированного слоя

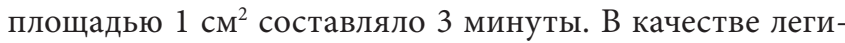
рующего электрода (анода) использовались хромони- келевые стали: 12Х18Н10Т, 08Х22Н6Т, 14Х17Н2, 20Х13, 12ХН3А; жаростойкий сплав Х20H80-Н. Чистые металлы $\mathrm{Cr}$ и $\mathrm{Ni}$ использовались в работе в качестве анодного материала для сопоставления свойств покрытий, полученных из хромоникелевых сплавов, с покрытиями, полученными при электроискровом легировании $\mathrm{Cr}$ и $\mathrm{Ni}$. В качестве основы для нанесения покрытий использовали сталь 45 , являющуюся наиболее распространенным конструкционным материалом.

Микроструктура измененного поверхностного слоя исследовалась на металлографическом микроскопе МИМ-10. Исследование образцов с покрытиями на окисляемость выполнялось методом дифференциально-термического анализа на дериватографе Q-1000 в интервале температур $25-1000^{\circ} \mathrm{C}$ со скоростью нагрева $10^{\circ}$ мин и последующим равномерным охлаждением образцов. Удельный прирост массы $\Delta m / S$ рассчитывался для каждых $100^{\circ} \mathrm{C}$. Полученные результаты обработаны методами математической статистики. Исследования жаростойкости образцов выполнялись в муфельной печи ПМ-12М2 с выдержкой 7 часов при температуре $730^{\circ} \mathrm{C}$. Распределение химических элементов в измененном поверхностном слое стали 45 изучали с помощью рентгеновского микроанализатора МАР-3.

\section{3. Результаты и обсуждение}

Для рассмотрения характера поведения легирующих элементов в поверхностно модифицированных образцах стали 45 исследуемые объекты подвергались равномерному нагреву до $1000^{\circ} \mathrm{C}$. На Рис. 1а представлена динамика окисления образцов в диапазоне температур $200-1000^{\circ} \mathrm{C}$ с покрытиями, полученными с помощью электроискрового легирования из чистых металлов и хромоникелевых сплавов. Экспериментально установлено влияние разного химического состава материалов легирующих электродов на окисляемость формируемых ими покрытий при нагреве до $1000^{\circ} \mathrm{C}$. Видно, что стойкость к окислению сформированного слоя зависит от комбинации в нем легирующих элементов, передаваемой материалом анода при электроискровом легировании. Из рассматриваемых хромоникелевых электроискровых покрытий наибольшее сопротивление высокотемпературному окислению проявляют образцы, легированные именно жаростойкими материалами Х20H80-H, 12Х18Н10T, 20Х13, что выражается в наименьшем удельном приросте массы образцов (Рис. 1a). 


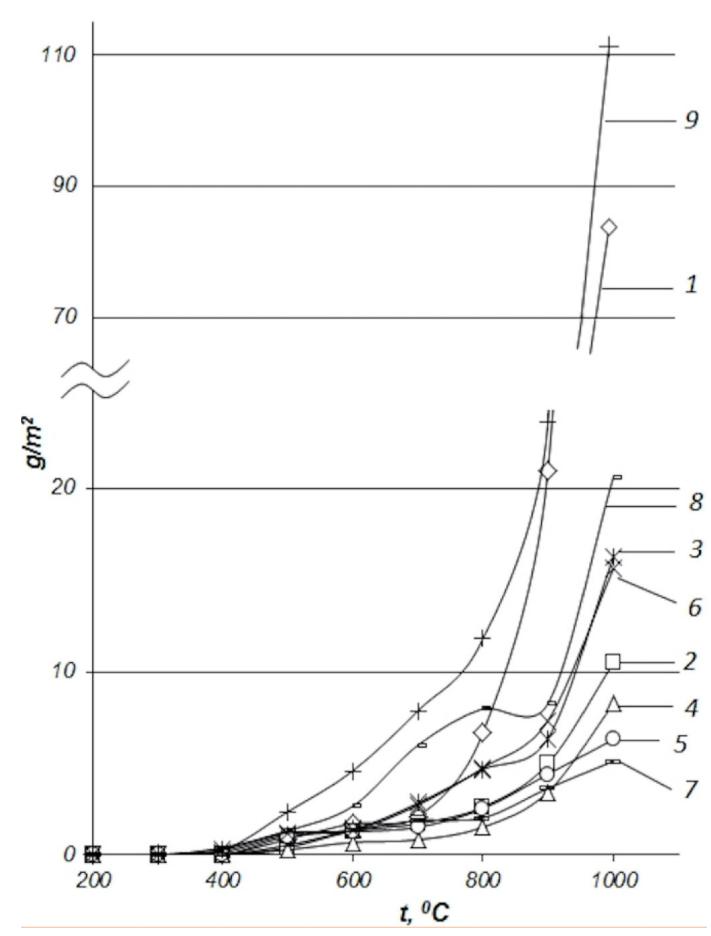

a

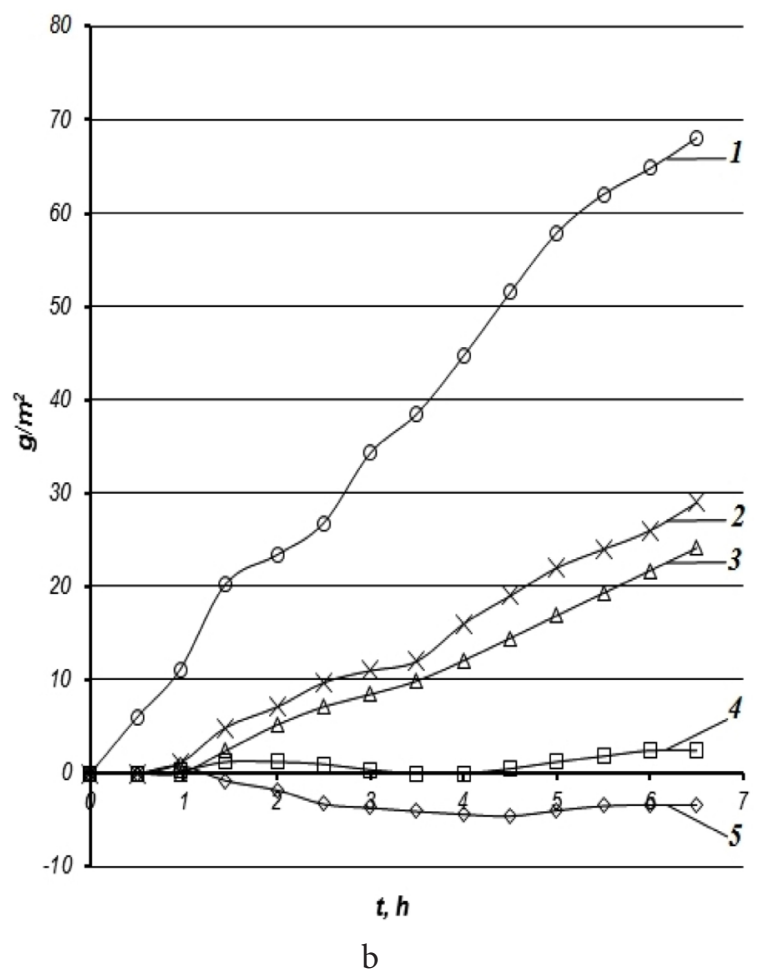

b

Pис. 1. Исследования окисляемости и жаростойкости покрытий на стали 45, сформированных при электроискровом легировании: динамика удельного прироста массы образцов с покрытиями при нагреве до $1000^{\circ} \mathrm{C}$ (материал легирующего электрода: $1-$ сталь 45 без покрытия; 2 - сталь 20Х13; 3 - сталь 14Х17Н2; 4 - сталь 12Х18Н10T; 5 - сплав Х20H80-Н; 6 - сталь 08Х22Н6T; 7 - Сr; $8-\mathrm{Ni} ; 9$ - сталь 12ХН3А) (а); динамика удельного прироста массы образцов с покрытиями при температуре $730^{\circ} \mathrm{C}$ и выдержке в течение 7 часов (материал легирующего электрода: 1 - сталь 45 без покрытия; 2 - сталь 20Х13; 3 - сталь 12Х18Н10Т; 4 - сплав $\mathrm{X} 20 \mathrm{H} 80-\mathrm{H} ; 5$ - Cr) (b).

Fig. 1. Research on oxidation susceptibility and heat resistance of coatings deposited on steel C45 in ESA: specific mass increment of coated samples heated up to $1000^{\circ} \mathrm{C}$ (material of an alloying electrode: 1 - not coated steel C45;2 - steel X20Cr13;3 - steel X20CrNi72; 4 - steel X12CrNiTi18-9; 5 - alloy NiCr80-20; 6 - steel X8Cr22Ni6Ti; 7 - Cr; 8 - Ni; 9 - steel 12Ni14) (a); specific mass increment of coated samples heated up to $730^{\circ} \mathrm{C}$ and 7-hour exposure (material of an alloying electrode: 1 - not coated steel C45; 2 - steel X20Cr13; 3 - steel X12CrNiTi18-9; 4 - alloy NiCr80-20; 5 - Cr) (b).

Это согласуется с литературными данными окалиностойкости материалов и экспериментально полученными значениями их окисляемости (Табл. S1, дополнительный материал), где наименьший удельный прирост массы жаростойких электродных материалов соответствует наименьшему приросту массы сформированных при электроискровом легировании покрытий. Такое поведение покрытий объясняется способностью легирующего компонента $\mathrm{Cr}$ и (или) $\mathrm{Ni}$ и основного металла подложки Fe образовывать неограниченные твердые растворы при электроискровом легировании в структуре измененного поверхностного слоя образца.

При дифференцированном термическом анализе с повышением температуры образцов происходит увеличение скорости диффузии легирующих элементов и образование в легированном слое сплошной пленки защитных оксидов и шпинелей на основе $\mathrm{Cr}$, Ni и $\mathrm{Fe}$ $\left(\mathrm{Cr}_{2} \mathrm{O}_{3}, \mathrm{Fe}_{3} \mathrm{O}_{4}, \mathrm{NiO}, \mathrm{FeCr}_{2} \mathrm{O}_{4}, \mathrm{NiFe}_{2} \mathrm{O}_{4}, \mathrm{NiCr}_{2} \mathrm{O}_{4}\right)$. Среди жаростойких материалов стойкость к высокой температуре легированному слою придает сплав Х20Н80-Н, не имеющий в химическом составе углеродного компонента. Сравнивая динамику окисления поверхностного слоя хромом и сталью 20Х13, также можно заметить влияние углеродной составляющей, где низкое содержание последней в материале анода при повышении содержания Cr снижает окисляемость покрытия.
Диффузию $\mathrm{Cr}, \mathrm{Ni}$ и Fe в сформированном после электроискрового легирования слое образца можно наблюдать на Рис. 2. На графиках слева направо (от легированного слоя к основе образца) четко выделяются три зоны: смешивания, диффузионная и подложки. Видна однородность и постоянство концентрации легирующих элементов, проникающих по всему объему зоны формирования измененного поверхностного слоя, что вызвано гомогенным перемешиванием расплава вследствие термомеханического воздействия при электроискровом легировании. На пористость легированного слоя указывает множество вершин и впадин профилей, амплитуда которых увеличивается с увеличением содержания $\mathrm{Ni}$ в легированном слое. Металлографическими исследованиями после высокотемпературного окисления установлено сохранение адгезии электроискровых покрытий из жаростойких сплавов с легируемой поверхностью образца и высокой сплошности (более 97,8\%) (Таб. S2, дополнительный материал).

Также установлено снижение качества покрытия, сформированного при электроискровом легировании сталью $12 \mathrm{XH} 3 \mathrm{~A}$, что определило значение максимального окисления сформированного слоя среди исследуемых покрытий. Низкое содержание $\mathrm{Cr}$ и $\mathrm{Ni}$ достаточно для образования неограниченных твердых растворов в легированном слое при электроискровом легировании 

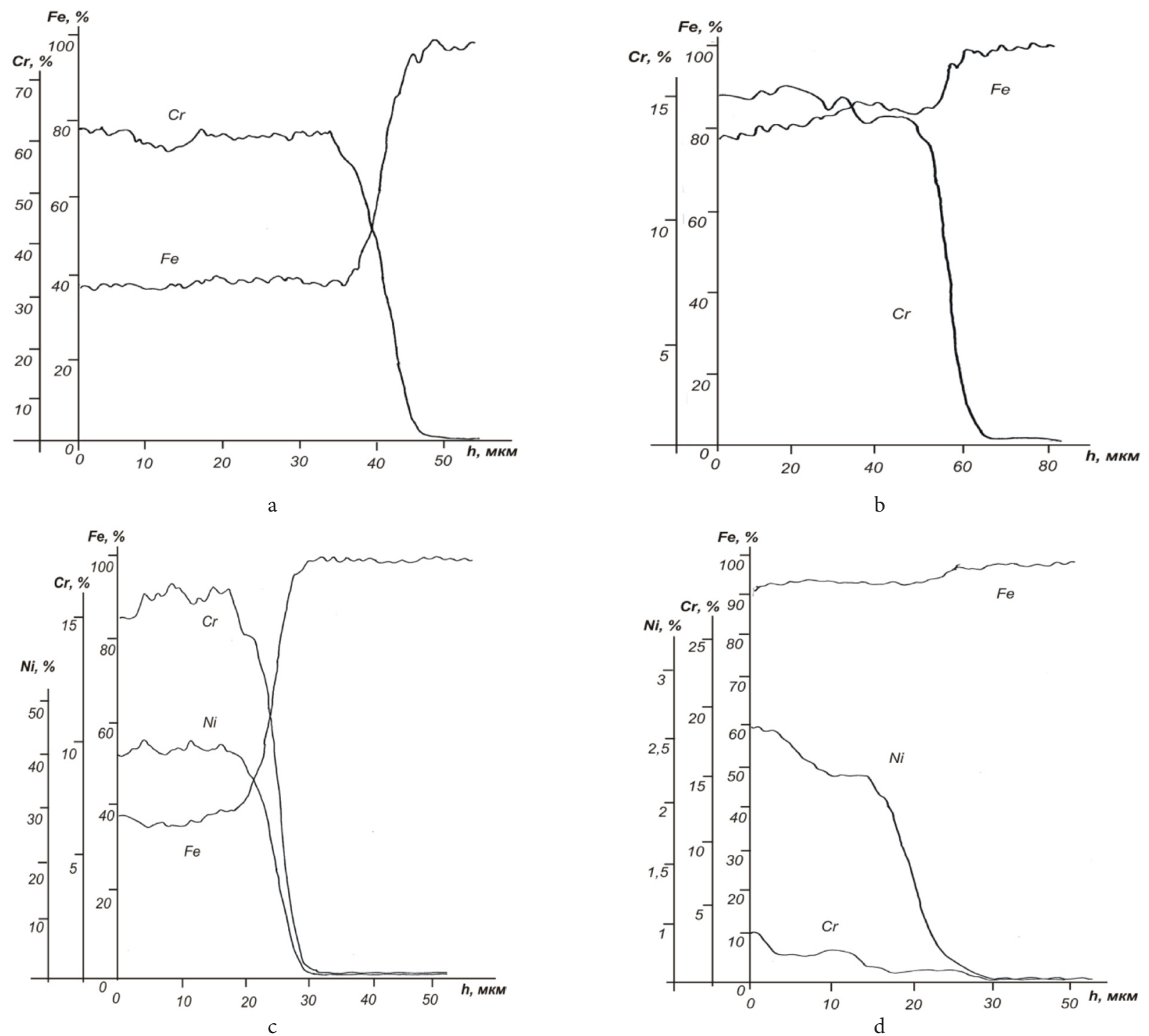

Рис. 2. Распределение элементов в измененном поверхностном слое, полученном после электроискрового легирования стали 45. Легирующий материал: $\mathrm{Cr}$ (a), 20X13 (b), X20H80-H (c), 12XH3А (d).

Fig. 2. Elements distribution in modified surface layers obtained after ESA of steel C45. Alloying material: Cr (a), X20Cr13 (b), NiCr80-20 (c), 12Ni14 (d).

и повышения условия его формирования, но недостаточно для образования защитных оксидов и шпинелей, способных противостоять активному окислению железа подложки. Сильное окисление связано с образованием вюститной фазы $\mathrm{FeO}$, кристаллическая решетка которой характеризуется большим числом вакансий, создавая благоприятные условия для диффузии $\mathrm{Fe}^{2+}$ к поверхности металла. Напротив, незначительное уменьшение толщины легированного слоя в структуре измененного поверхностного слоя других исследуемых образцов после проведения экспериментов методами дифференциального термического анализа [10] связано с замедлением скорости окисления и формированием жаростойких фаз в покрытиях.

В условиях повышенной нагрузки детали из конструкционных сталей могут длительно подвергаться газовой коррозии. На Рис. $1 \mathrm{~b}$ представлена динамика удельного прироста массы образцов при окислении в муфельной печи. Установлено сохранение тенденции сопротивления образцов газовой коррозии при проведении дифференциального термического анализа и жаростойкого испытания в ряду легированных слоев, образуемых хромом - хромоникелевым сплавом - жаростойкими сталями, где хромовое покрытие проявляет наибольшую стойкость к термическому воздействию. Подтверждается негативное влияние углерода сталей на термостабильность образуемых при электроискровом легировании покрытий. Например, в случае легированного слоя из стали 20X13 на поверхности образуется сетка микротрещин (Рис. За), которая является следствием возникновения внутренних напряжений в поверхностном слое и отсутствием его пластичности. Происходит разложение поликарбидов хрома с дальнейшим окислением углеродной фазы. Микротрещины открывают доступ кислорода к подложке, способствуя тем самым запуску механизма окисления железа с образованием его возможных оксидных фаз $\mathrm{FeO}, \mathrm{Fe}_{2} \mathrm{O}_{3}, \mathrm{Fe}_{3} \mathrm{O}_{4}$. Напротив, присутствие $\mathrm{Ni}$ в жаростойких хромонике- 


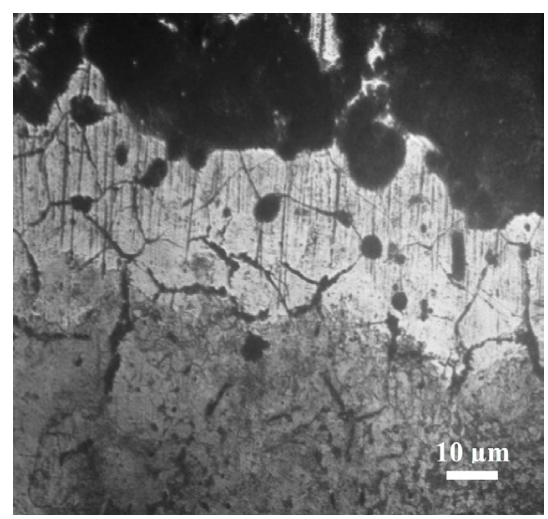

a

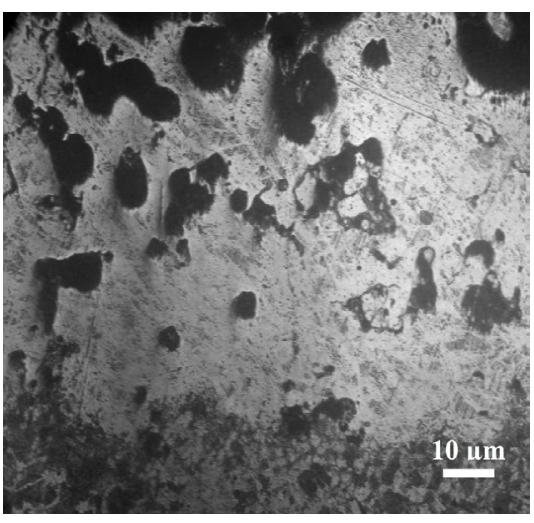

$\mathrm{b}$

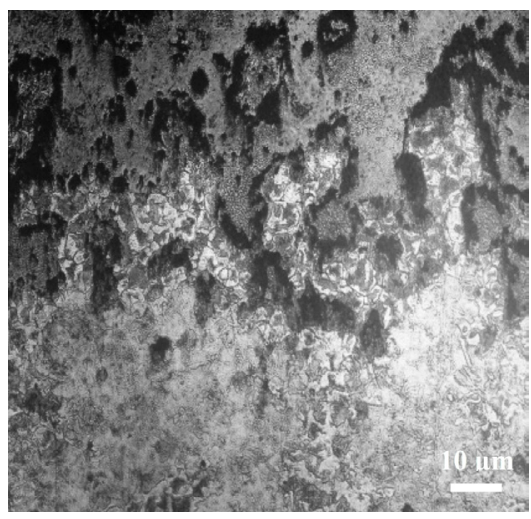

c

Рис. 3. Вид покрытий, образуемых электроискровым легированием, после высокотемпературных испытаний: микроструктура измененного поверхностного слоя стали 45 после исследований на жаростойкость $\left(T=730^{\circ} \mathrm{C}, \quad \tau=7 \quad\right.$ час, воздух), легирующие материалы: сталь $20 \mathrm{X} 13$ (а), сплав X20H80-H (b); после исследований на окисляемость до $1000^{\circ} \mathrm{C}$, легирующий материал $12 \mathrm{XH} 3 \mathrm{~A}(\mathrm{c})$.

Fig. 3. ESA coatings after high-temperature tests: microstructure of the modified surface layer of steel 45 after heat-resistance tests $\left(\mathrm{T}=730^{\circ} \mathrm{C}\right.$, $\tau=7$ hours, air), alloying materials: steel $\mathrm{X} 20 \mathrm{Cr} 13$ (a), alloy $\mathrm{NiCr} 80-20$ (b); after tests of oxidation susceptibility up to $1000^{\circ} \mathrm{C}$, alloying material $12 \mathrm{Ni1} 4$ (c).

левых электродных материалах придает пластичность сформированным защитным слоям, которая сохраняется даже в течение длительного термического воздействия (Рис. 3b). Сопоставляя результаты металлографического анализа и результаты испытаний на жаростойкость необходимо заключить, что не наблюдается корреляции между макроструктурными характеристиками легированного слоя (толщиной, сплошностью, пористостью) и изменением свойств образцов при высоких температурах. Определяющим фактором в условии формирования термостойкого легированного слоя является образование неограниченных твердых растворов с оптимальной комбинацией основных присутствующих легирующих элементов $\mathrm{Cr}$ и $\mathrm{Ni}$.

Согласно теории жаростойкого легирования В.И. Архарова, изложенной в [18], повышение жаростойких свойств железных сплавов может быть достигнуто при соблюдении двух условий: 1) устранение при окислении железа на поверхности соединений со структурой вюстита; 2) образование на поверхности сплава оксидов типа шпинели с возможно меньшими параметрами кристаллической решетки. Сопоставляя результаты окисляемости электроискровых покрытий с исследованиями их фазового состава [10] и теорией В.И. Архарова [18], можно утверждать, что они находятся в полном соответствии. Например, сильное окисление легированного слоя на стали 45, модифицированной сплавом $12 \mathrm{XH} 3 \mathrm{~A}$ (Рис. 3c), может быть связано только с образованием большого количества оксида железа $\mathrm{FeO}$ с кубической решеткой. В этом оксиде содержится кислород в превышающих стехиометрические значения количествах. Известно, что температура устойчивости вюстита $575^{\circ} \mathrm{C}$. При такой температуре скорость окисления железа сильно возрастает. В кристаллической решетке образуется большое количество вакансий, тем самым, создавая благоприятные условия для диффузии $\mathrm{Fe}^{2+}$ к поверхности и перемещения электронов посредством перехода $\mathrm{Fe}^{2+} \leftrightarrow \mathrm{Fe}^{3+}+\mathrm{e}^{-}$.
Возможность образования вюститной фазы будет затруднена, если в состав железа ввести легирующие элементы, способствующие образованию двойных оксидов типа $\mathrm{FeCr}_{2} \mathrm{O}_{4}, \mathrm{NiFe}_{2} \mathrm{O}_{4}, \mathrm{NiCr}_{2} \mathrm{O}_{4}$ и др. Экспериментально это подтверждается формированием легированного слоя из $\mathrm{Cr}, \mathrm{Ni}$ и жаростойких хромоникелевых материалов, образующих неограниченные твердые растворы. При высокотемпературном воздействии они более склонны к образованию защитной пленки шпинельной структуры $-\mathrm{NiO} \cdot \mathrm{Cr}_{2} \mathrm{O}_{3}$.

Примером защитных свойств шпинельных структур при высокотемпературном окислении является покрытие из $\mathrm{Cr}$ и сплава Х20H80Н. Образование на поверхности соединений типа $\mathrm{FeO} \cdot \mathrm{Me}_{2} \mathrm{O}_{3}$ или $\mathrm{Fe}_{2} \mathrm{O}_{3} \cdot \mathrm{MeO}$, является следствием меньшего ионного радиуса $\mathrm{Cr}$ и $\mathrm{Ni}$ по сравнению с железом. Вероятность образования подобных защитных соединений зависит от объема основных присутствующих легирующих элементов $\mathrm{Cr}$ и $\mathrm{Ni}$ в легированном слое, что определяет его структуру.

На основании полученных экспериментальных данных по хромоникелевым покрытиям можно сделать вывод о наиболее сбалансированном соотношении легирующих элементов в измененном поверхностном слое: $\mathrm{Cr}-15$ вес. \% и $\mathrm{Ni}-40$ вес. \%, позволяющем при термическом воздействии образовывать на поверхности защитные структуры, сопротивляться окислению, защищая подложку. Из Рис. $1 \mathrm{~b}$ видно, что даже через три часа высокотемпературного воздействия изменение удельного прироста массы образца незначительно. Происходит адаптация покрытия к высокой температуре, перераспределение фаз и быстрое формирование на поверхности окалины из оксидов $\mathrm{Cr}_{2} \mathrm{O}_{3}$ и $\mathrm{NiO}$. Такая устойчивая комбинация легирующих элементов в измененном поверхностном слое позволяет не только проявлять жаростойкость, сохраняя пластичность, но длительно защищать подложку прочными оксидами $\mathrm{Cr}_{2} \mathrm{O}_{3}, \mathrm{NiO}$ и продуктом их высокотемпературных превращений $\mathrm{NiCr}_{2} \mathrm{O}_{4}$. 


\section{4. Выводы}

1. Установлено, что на способность электроискровых покрытий длительно сопротивляться высокой температуре оказывает приоритетное значение химический состав легированного слоя, а не его макропараметры сплошность, пористость толщина.

2. Установлено, что для защиты конструкционных сталей методом электроискрового легирования от газовой коррозии при $730^{\circ} \mathrm{C}$, необходимо использовать легирующий электрод из жаростойкого сплава Х20H80-Н, формирующий в процессе легирования защитный слой со сбалансированным термостойким соотношением Cr 15 вес.\% и Ni 40 вес.\% на основе неограниченных твердых растворов с Fе материала подложки.

Благодарность/Acknowledgements. Исследование выполнено при финансовой поддержке Министерства образования и науки Российской Федерации (соглашение №14.578.21.0228, уникальный идентификаmop paбom (проекта) RFMEFI57817X0228)./The study was carried out with the financial support of the Ministry of Education and Science of the Russian Federation (agreement No. 14.578.21.0228, unique identifier of the work (draft) RFMEFI57817X0228).

Дополнительный материал/Supplementary Information. Электронная версия статьи содержит дополнительный материал (таблицы S1-S2), доступный безвозмездно на сайте журнала (www.lettersonmaterials.com). / The online version of this paper contains supplementary material (tables S1-S2) available free of charge at the journal's Web site (www.lettersonmaterials.com).

\section{Литература/References}

1. A.V. Ribalko, O. Sahin. Surface and Coatings Technology. 201(3-4), $1724 \quad$ (2006). DOI: $10.1016 /$ j.surfcoat.2006.02.044

2. F.I. Panteleenko, V.V. Sarantsev, A.M. Stolin, P.M. Bazhin, E.L. Azarenko. Surface Engineering and Applied Electrochemistry. 47(4), 328 (2011). DOI: $10.3103 /$ S1068375511040107

3. A.V. Ribalko, O. Sahin, K. Korkmaz. Surface and Coatings Technology. 203(23), 3509 (2009). DOI: $10.1016 /$ j.surfcoat.2009.05.002

4. V. I. Agafii, V. I. Petrenko, V. M. Fomichev, V. I. Yurchenko, E.V. Yurchenko, A.I. Dikusar. Surface Engineering and Applied Electrochemistry. 49(3), 181 (2013). DOI: $10.3103 /$ S1068375513030022

5. A.D. Verkhoturov, L.A. Konevtsov, A. M. Shpilev A.M., P.S. Gordienko, E.S. Panin, I.A. Podchernyaeva, A.D. Panasyuk. Powder Metallurgy and Metal Ceramics.
47(1 - 2), 112 (2008). DOI: 10.1007/s11106-008-0015-2

6. A.D. Verkhoturov, V.M. Makienko, L.A. Konevtsov, V. Y. Vostrikov. Scientific notes of Komsomolsk-on-Amur State Technical University. 1(4), 69 (2015). (in Russian) [А.Д. Верхотуров, В.М. Макиенко, Л.А. Коневцов, В.Я. Востриков. Ученые записки Комсомольскогона-Амуре государственного технического университета. 1(4), 69 (2015).]

7. A.D. Verkhoturov, I. A. Podchernyaeva, A.D. Panasyuk, N. M. Potapova, V. G. Radchenko, N. S. Stolyarova. Soviet powder metallurgy and metal ceramics. 27(3), 238 (1988). DOI: $10.1007 / B F 00802601$

8. Z. O. Dolgiy, W.Z. Shao, A.V. Kozyr, S. V. Martynov. Advanced Materials Research. 538-541, 175 (2012). DOI: 10.4028/www.scientific.net/AMR.538-541.175

9. V.V. Mikhailov, A.E. Gitlevich, A.D. Verkhoturov, A. I. Mikhailyuk, A. V. Belyakov, L. A. Konevtsov. Surface Engineering and Applied Electrochemistry. 49(5), 373 (2013). DOI: 10.3103/S1068375513050074

10. V.P. Luneva, A. D. Verhoturov, A. V. Kozyr, T. V. Glabets, V.N. Bruy. Elektronnaya Obrabotka Materialov. 41(4), 11 (2005). (in Russian) [В.П. Лунева, А.Д. Верхотуров, А.В. Козырь, Т.В. Глабец, В.Н. Бруй. Электронная Обработка Материалов. 41(4), 11 (2005).]

11. V. I. Ivanov, A. D. Verkhoturov, L. A. Konevtsov. Surface Engineering and Applied Electrochemistry. 53(3), 218 (2017). DOI: $10.3103 /$ S1068375517030061

12. A. A. Burkov. Welding International. 32(1), 72 (2018). DOI: 10.1080/09507116.2017.1382078

13. S. V. Nikolenko, N. A Syui. Protection of Metals and Physical Chemistry of Surfaces. 53(5), 889 (2017). DOI: 10.1134/S207020511705015X

14. A.V. Belyakov, A.N. Gorbachev, V.V. Mikhailov, B.F. Reutov, A.A. Fokin. Surface Engineering and Applied Electrochemistry. 53(3), 274 (2017). DOI: $10.3103 /$ S1068375517030036

15. S. V. Nikolenko, A.D. Verkhoturov, N.A. Syui, E.N. Kuz'michev. Surface Engineering and Applied Electrochemistry, 52(4), $342 \quad$ (2016). DOI: $10.3103 /$ S1068375516040098

16. V.I. Ivanov, A.D. Verkhoturov, L.A. Konevtsov. Surface Engineering and Applied Electrochemistry. 53(3), 224 (2017). DOI: $10.3103 /$ S1068375517030073

17. A. A. Burkov, S. A. Pyachin, A. V.Zaytsev, E. A. Kirichenko, M.A. Teslina, N.A. Syuy. Letters on materials. 6(3), 163 (2016). (in Russian) [A.A. Бурков, С.А. Пячин, А.В. Зайцев, Е.А. Кириченко, М.А. Теслина, Н.А. Сюй. Письма о материалах. 6(3), 163 (2016).] DOI: $10.22226 / 2410-3535-2016-3-163-167$

18. I. V. Semenova, G. M. Florianovich, A. V. Khoroshilov. Corrosion and corrosion protection. Moscow, Fizmatlit (2002) 336 p. (in Russian) [И.В. Семенова, Г. М. Флорианович, А. В. Хорошилов. Коррозия и защита от коррозии. Москва, Физматлит (2002) 336 с.] 